\title{
Do fideicomisso nas doações inter-vivos
}

Alvino Lima

A validade do fideicomisso, nas doações inter-vivos, tem suscitado, entre nós, radicais divergências de opinião, em face dos dispositivos legais disciplinadores da matéria no Código Civil.

A disparidade de opiniões, no direito anterior, mais se acentuou em face do Código Civil, que, regulando a matéria, dela só tratou no capítulo do testamento.

Sustentando a nulidade da cláusula fideicomissária nas doações inter-vivos, podemos citar as opiniões valiosas de Carlos Maximiliano, "Direito das Sucessões", II, n. 1.242; Ferreira Alves, "Manual de dir. civ. br." ed. P. Lacerda, vol. XIX, ns. 251-252; Carvalho Santos, "Cód. civ. br. int.", vol. XIV, pags. 171 e segs; Itabaiana, "Dir. das Sucessões", pag. 171 e segs; Jorge AMERICANo, "Direito", vol. 1, pags. 159 e segs.; NoÉ Azevedo, Parecer, em "Revista dos Tribunais", vol. 124, pag. 41.

Em sentido contrário se inscrevem Philadelpho Azevedo, "Direito", vol. VI, pag. 51; Francisco Morato, "Revista dos Tribunais", vol. 44/444; Mendes Pimentel, "Revista dos Tribunais", vol. 95/56; Alfredo Bernardes, "Revista dos Tribunais", vol. 56/247; Vieira Ferreira, "Revista Forense", vol. 55/140; Laudo Camargo, "Revista dos Tribunais", vol. 76/81; Antonino Vieira, "Revista dos Tribunais", vol. 102/466 e outros.

A controvérsia, como se vê pela autoridade dos que escreveram sobre o assunto, é digna de ser apreciada e subme- 
tida a novos estudos, todas as vezes que surge nos debates judiciários.

Ainda recentemente o Prof. Jorge Americano, em artigo publicado no "Direito", sob o título "Fideicomisso por ato entre vivos", estudou novamente o assunto, negando a validade das substituições fideicomissárias nas doações intervivos.

Verificamos, em síntese, que o ilustre professor nega a validade do referido fideicomisso, pelas razões seguintes:

a) O fideicomisso nas doações inter-vivos contém um pacto de sucedendo, proibido pelo art. 1.089 do Código Civil.

b) $O$ fideicomisso é forma de substituição e na lei só tem lugar no direito sucessório.

c) Se o nosso Código quisesse admití-lo no nosso direito, teria feito como no português, que o admite tambem nas doações, de modo expresso.

d) A disposição a favor de pessoa que não tem parte no ato ou seja o fideicomissário, não póde caber no ato bilateral de doação, mas só no unilateral, causa-mortis.

e) Não cabe no caso a interpretação analógica, visto como a matéria da substituição é de lei especial.

Colocando-nos entre os defensores da substituição fideicomissária nas doações inter-vivos, procuramos refutar os argumentos enumerados.

a) Do pacto succedendo nas doações fideicomissárias.

0 argumento de que o fideicomisso nas doações intervivos contém um pacto successório, já foi respondido pelo emérito professor MORATO nos seguintes termos:

"Não colhe dizer tampouco que o fideicomisso implica pacto successório, como sustentava Luz TeIXeira. 
Pacto de sucedendo é o que alguem promete a outrem instituí-lo herdeiro ou transfere a terceiro o direito de suceder na herança de pessoa viva (Cód. Civ., art. 1.089. Ord. L. 4, Tit. 70, $§ 3 .^{\circ}$. LAFAYETTE, not. IV em apêndice do "Direito de família").

Ora, nada disso se dá no fideicomisso, que, realizado por doação, exprime apenas a liberalidade do doador em favor de duas pessoas, uma para colher o beneficio depois da outra.

Não há aí contrato algum sobre herança de pessoa viva; não há aí pacto nenhum, em que um dos pactuantes prometa instituir outro por seu herdeiro ou transfira a terceiro o direito de suceder na herança de pessoa viva.

O que aí há é só e só uma doação com uma cláusula que nada tem de reprovado".

Mas o ilustre professor poderia avançar nos seus conceitos, estudando, nos seus requisitos, o pacto sucessório, afim de reforçar a improcedência da objeção. Senão vejamos.

Dentre os requisitos dos pactos sucessórios, os escritores destacam o seguinte:

A convenção deve ter por fim direto a regulamentação particular de uma sucessão ou que tenha sido feita na espectativa de uma sucessão (vide Demogue, "Traité des obligations", vol. II, n. 855; J. Bonnecase, "Sup. ao Tr. de Baudry", vol. VI, n. 308; GIORGI, "Teoria delle Obbligazioni", III, n. 333; C. de MendonçA, "Obrigações", vol. II, pag. 247).

O que carateriza, portanto, a convenção sobre a herança de pessoa viva é a regulamentação direta de uma sucessão não aberta, creando um direito privativo à mesma. Neste sentido podemos consultar vários julgados dos tribunais franceses, onde é abundante a matéria, pelo aparecimento de vários contratos referentes a direitos futuros dependentes da morte de uma das partes. No "Code Civil annoté" 
de Fuzier-Hermann, edição de Demogue, vol. III, pag. 137 e segs., destacamos os julgados ns. 96 e 101 :

"Pour qu'une convention tombe sous la prohibition édictée par l'art. $1.130 \mathrm{C}$. civ., il est necessaire qu'elle tende à disposer dans un sens quelconque d'un actif dépendant ou devant dépendre d'une succession non encore ouverte, et d reconnaitre, retirer ou discuter le droit d'une des parties dans cette succession".

"En effet, par la clause du contrat de mariage ci-dessus analysée, le mari, ayant disposé, pour le temps où il n'existerait plus, de ses droits dans la société, une tel stipulation aurait pour objet d'attribuer un droit privatif dans une succession non ouverte, et du moment que les droits sociaux étaient attribués à la veuve contre versement de leur valeur aux héritiers de celui-ci, donc à titre onéreux, elle tombait nécessairement sous le coup de la prohibition des pactes sur succession futures, était nulle de plein droit, et il ne pourrait en être fait état à quelque titre que ce soit".

No mesmo sentir, conceituando que o pacto sucessório deve ser feito na previsão da abertura da sucessão, podemos consultar a coletânea de julgados italianos dirigida por FadDA e outros ("Prima raccolta completa della Giur. sul Codice Civ"., vol. V, pags. 201 e segs.).

Ora, se considerarmos o que acabamos de afirmar, em face da doutrina aceita pelos Tribunais, verificaremos que na doação inter-vivos, com a cláusula de substituição fideicomissária, não se regulamenta uma sucessão futura, não se cria um direito privativo a esta sucessão, mas apenas surge um direito eventual do fideicomissário a um determinado bem, não se cuidando da sucessão de quem quer que seja.

Pouco importa que o direito do fideicomissário esteja sujeito a um termo ou condição - a morte do fiduciário, por exemplo, visto como não é o mesmo um direito diecon- 
rente da sucessão, de quem quer que seja, mas um direito que apenas pode coincidir com a abertura de uma sucessão; a lei não proíbe os atos visando uma sucessão futura, fazendo intervir o ato de sua abertura, sob fórma de termo ou condição, desde que não encerre a regulamentação da sucessão não aberta (vide DemoGue, obr. cit., n. 857).

Mas não é só.

No pacto sucessório é indispensavel que o contraente tenha agido na qualidade de herdeiro eventual, dispondo e contratando sobre bens, que ele deverá adquiirir por fôrça da henança, não fazendo mais do que alienar ou obrigar estia espectativa sucessória; consequentemente, se a convenção não é feita a título hereditário, mas a título diverso, terá valor (vide Ferrara, "Il negozio illicito", pag. 108; Grorgi, obr. cit., n. 333).

E' evidente que a doação feita ao donatário, máximè por estranho, com a cláusula fideicomissária a favor dos filhos ou sucessores do mesmo, não envolve bens de herança futura, porquanto o doador, na qualidade de proprietário do imovel, transfere o seu domínio ao donatário, e, posteriormente, verificado o termo ou condição, ao substituto.

Diz Adrien Liosa, "Des pactes sur successions futures", cit. por BonNeCASE, (obr. cit., pag. 413) :

"La troisième condition pour qu'il ait pacte sur succession future est que la chose qui en fait l'objet soit considérée comme devant revenir au promettant $\dot{a}$ titre successif, c'est-à dire lui revenir par la dévolution successorale normale".

Eis porque Giongi (obr. cit., pag. 463), estudando o caso da reversão da coisa doada ao doador, nos termos prometidos pelo Cod. civ. it., interroga se ha no caso um pacto sucessório, respondendo negativamente, visto como a coisa retorna ao doador, por força de um direito de crédito, independente da sucessão.

Nas mesmas condições se acha o fideicomissário; o seu direito ao imovel não decorre da sucessão do fiduciário, mas 
é um direito próprio, embora sventual, que nasce da própria doação; a abbertura da sucessão é apenas a condição para que surja o seu direito de propriedade.

Eis porque dizem BAUDRY-BARDE:

“L'appelé n'a pas seulement une espérance; il a d'ores et dejà un droit conditionnel; c'est si vrai que, de l'avis de tous les auteurs, il peut, à difference de l'héritier présomptif, faire de actes conservatoires. Le art. 1.130 ne lui est donc pas applicable, et, par suite, il faut admettre que rien ne l'mpêche de disposer de son droit".

Conferem: Aubry et RaU ("Dir. civ. fr.", vol. XII, pag. 276; Braudry-Colin ("Donazioni fra vivi", tr. it. de Ascoly e Bonfante, II, n. 3408).

O fideicomissário, é, pois, titular de um dineito próprio, direito condicional ou eventual, visto como não the advém do fiduciário, mas do donatário, por fôrça da estipulação a favor de terceiro (vide Alex WeILl, "La relativité des conventions en droit privé français", n. 480; Planiol-RrpertTrasbot, "Donations et Testaments", n. 813; Bonnecase, "Suplement" cit., vol. III, n. 566; Baudry-Colin, obr. cit., II, ns. 3143 e 3403; Colin e Capitant, "Derecho civ. fr.", tr. hesp., de DE BuEn, vol 8, pag. 172).

Outro não é o sentir dos nossos juristas, não só comentando os dispositivos referentes à estipulação a favor de terceiros, como os referentes ao fideicomisso (vide C. MAximiliano, obr. cit., n. 1275; C. Santos, obr. cit., vol. XV, pag. 303; vol. XXIV, pag. 200).

Neste sentir a lição de Corrêa de Merra é profundamente judiciosa :

"Note-se bem, o fideicomissário tem o seu direito não do fiduciário, mas do autor da liberalidade. Isto posto, como falar de herança de pessoa viva? Como falar, que o fideicomissário sucede ao fiduciário? Ora, se ambos têm o seu 
direito, derivado do doador, como vir falar em pactos sucessórios sem grave equívoco?

Esta simultaneidade dos direitos do fiduciário e do fideicomissário é conforme o conceito legal.

0 art. 1.775 do Cod. Civil diz que o fideicomissário pode renunciar à propriedade que, neste caso, ficará pura do fiduciário.

Ora, como renunciar sem ter direito? 0 art. $1.738 \mathrm{diz}$ que falecendo o fideicomissário "a propriedade consolida-se no fiduciário". Se só após a morte do fideicomissário a propriedade se consolida, se integra, se completa, é porque antes não era senão parcial. Diz mais o art. 1.735 que a propriedade do fiduciário é restrita e resoluvel. Ora, não compreendemos propriedade restrita e plena ao mesmo tempo. Se ela é restrita é porque alguma outra pessoa tambem a tem.

Dada a simultaneidade dos direitos do fiduciário e do fideicomissário, dada a filiação direta à pessoa do bemfeitor, manifesto é, este pacto sucessorio não passa de uma balela, de uma fantasia literária. Aliás, bem vimos, jamais deixou de ser acatado no Brasil e nas nações em geral o fideicomisso por doação inter-vivos".

Verifica-se, pois, do exposto, que a doação inter-vivos com a cláusula de substituição fideicomissária não é um contrato, cuja finalidade seja a regulamentação de uma sucessão não aberta; o fideicomissário é titular de um direito próprio, só podendo ser considerado sucessor do fiduciário, no sentido de receber os bens que foram do patrimônio do mesmo fiduciário (vide Alex Weill, obr. cit., n. 480). 
b) O fideicomisso é forma de substituição regulada pelo direito sucessório e na lei só tem lugar neste direito.

Eis o segundo argumento de que lançam mão os adversários da doação inter-vivos com a cláusula fideicomissária.

Para desviar, desde logo, o argumento, demonstrando que a substituição fideicomissária não é matéria exclusiva de direito sucessório, bastaria considerar que a mesma é regulada no capítulo da doação nos códigos civis português e hespanhol, os quais admitem, respetivamente, nos arts. 1.473 e 641, a constituição da substituição fideicomissária nas doações inter-vivos. Tambem no Código Civil do Dominio do Canadá, segundo a lição de Emile Billette, é permitida a substituição fideicomissária nas doações inter-vivos ("Donation", em "Le droit civ. fr. - Livre-Souvenir des journées du droit civ. fr." - Sirey-1936, pág. 213).

Aliás, a matéria já nos veiu do direito romano, permitindo-se a doação inter-vivos com a referida cláusula, segundo o testemunho de Savigny, "Traité de droit romain" vol. IV, pag. 296 (Tr. fr. de Guenoux-Paris-1854) e De LucA, "Tract. de fideicom. disc.", 1841, cit. por Mucio Marnoni, "Fedecomesso", em "Enc. Giur. it.", vol. VI, 1. ${ }^{a}$ parte, pag. 961).

O mesmo se verificou nas leis bárbaras, no direito intermédio, permitindo-se a instituição do fideicomisso contratual (vide Mucio Mainoni, loc. cit.)

Verifica-se, pois, que o instituto jurídico não é privativo do direito sucessório, não tendo significação jurídica a afirmação de que o instituto só tem sido tratado na matéria das sucessões e não na das obrigações.

Aliás, se o assunto é tratado, de preferência, no direito das sucessões, a razão está em que, geralmente, a substituição fideicomissária é usada no testamento, como já observou o Professor Morato, no seu citado parecer.

Acresce que os Códigos Civis francês e italiano, quando se referem ao direito de reversão, restringem, expressamente, este direito sómente ao donatário, como se vê dos arts. 951 e 1.071 dos respectivos Códigos Civis. Ora, não seria neces- 
sária tal restrição se a substituição fideicomissária fosse um instituto exclusivo do direito sucessório e inaplicavel, pela sua natureza jurídica, às doações.

c) Restringindo o art. 1.174 do Código Civil a reversão em beneficio apenas do doador, não quis o legislador, como o português, no art. 1.473 do Código Civil, instituir a substituição fideicomissária.

Eis a terceira objeção que nos apresentam os impugnadores da tese que defendemos.

A objeção já foi devidamente respondida pelo ilustre desembargador Vieira Ferreira, a quem conferimos a palavra, transcrevendo os seus argumentos:

"O legislador brasileiro, nessa disposição, não cogitou dos fideicomissos. Bem pêco seria aqui o recurso ao brocardo Inclusio unius, exclusio alterius, porque não se trata no artigo 1.174 de um direito anômalo.

A cláusula de reversão ao doador supérstite seria lícita pelo sistema do Código Civil, ainda que não houvesse o artigo 1.174, cuja disposição é mero colorário de outras mais gerais, uma simples aplicação de princípios superiores.

Ora, quais são as instituições do Código Civil em que se acham os princípios interessados na solução do problema?

Os atos jurídicos em suas modalidades e o regimem da propriedade em geral.

Nos atos jurídicos a autonomia da vontade tem uma amplitude que só encontra barreiras nas disposições legais de carater absoluto: Código Civil intr. 17, arts. 81, 115, 256, 312, 1.512, $1.664 \mathrm{e}$ outros.

0 art.๑81 define ato jurídico "todo ato lícito que tenha por fim imediato adquirir, resguardar, transferir, modificar ou extinguir direitos". 
$\mathrm{O}$ artigo 118 permite nos atos jurídicos, adiarse a aquisição do direito, subordinando-se a eficácia do ato á condição suspensiva.

$E$ os arts. 119 e 124 permitem estipular-se no ato jurídico a extinção do direito pelo implemento da condição resolutiva ou pelo advento do termo legal.

Todas estas peças do maquinismo legal funcionam perfeitamente para se produzir uma doação com fideicomisso.

Confira-se ao donatário o direito extinguivel pela condição resolutiva de sobreviver outro benefíciado a algum fato certo ou incerto.

Conceda-se ao mesmo tempo a esse beneficiário o mesmo direito, subordinado à sua sobrevivência como condição suspensiva.

Que teremos com essas cláusulas, por si mesmas lícitas, senão uma doação com fideicomisso.

Considere-se agora o regimen da propriedade vigente no Código Civil.

0 art. 69 prevê a possibilidade legal da inalienabilidade quando define as coisas fóra do comércio.

Não bastaria para conferir à vontade particular o direito de tornar inalienaveis os bens do agente

Mas o art. 1.676 considera o doador autorizado a impor ao bem doado a cláusula de inalienabilidade temporária ou vitalícia.

Não ha, pois, desse lado, nenhum obstáculo á doação com cláusula fideicomissária.

Por outro lado o Código Civil, nos arts. 525 647 , reconhece de modo geral a propriedade resoluvel por advento de termo ou por implemento de de condição resolutiva.

E' justamente a propriedade do fiduciário, segundo o art. 1.734. 
Se os efeitos jurídicos de uma doação clausulada como a que se afigura, coincidem exatamente com os de um fideicomisso por testamento, a conclusão é que, embora omisso o Código Civil quanto á doação fideicomissária, ela se legitima, todavia, na aplicação precisa de seus artigos". (Rev. Trib. 75/3).

Mas às considerações claríssimas e juridicas do ilustre jurista, podemos acrescentar observações gerais sôbre a maneira de interpretar um texto de lei, rebuscando esta sovada e desprestigiada - vontade do legislador - sem procurar sondar, desde que a lei não proiba expressamente um determinado ato, outros elementos de real importância para a fixação da verdadeira iṇterpretação do texto legal.

Ninguem, talvez, com mais veemência do que JoAQuim DuALDE, catedrático de direito civil da Universidade de Barcelona, na sua obra - "Una revolución en la lógica del derecho" - profligou este elemento de interpretação, mostrando a ignorância do legislador, as lacunas da lei, as suas incoerências e absurdos.

Ao envez de nos apegarmos ao que Hans Reichel ("La ley e la sentencia", tr. hesp. de Villagrasa, pag. 90) chama o paragrafismo, isto é, submissão servil ao texto legal, para nele descobrirmos o que o legislador quís, quando não o disse, devemos recorrer aos interesses em jogo, procurando uma solução justa, em face dos dados gerais do direito.

E' com este critério que o professor Scholten, da Universidade de Amsterdam, preconiza a interpretação da lei, atendendo ao seu fim, como solução justa dos casos, procurando na tradição, nos costumes e na jurisprudência o sentido da norma legal ("L'interpretation de la loi et la justice" em "Annales de l'Institut de Droit Comparé de l'Université de Paris", vol. II, pag. 1 e segs.).

A interpretação da lei, procurando na sua finalidade a justa solução do caso, arreda as interpretações que nos levam a soluções perniciosas, pois como muito bem acentua 
DüALDE (obr. cit., pag. 233), o destino de um preceito é atuar sôbre a vida e percorrer uma linha fecunda de efeitos.

Ora, por que razão, não tendo o legislador expressamente proibido a substituição fideicomissária nas doações intervivos, vai o intérprete encontrá-la ou procurá-la na combinação dos textos, arredando da cena jurídica um instituto de efeitos salutares e que não colide com os princípios gerais da teoria dos atos jurídicos adotados pelo sistema do nosso Código Civil?

No artigo "Le legs avec charge, catégorie juridique", publicado no "Recueil d'études sur les sources du droit en l'honneur de François Geny", vol. II pag. 128, o professor Henri Simonnet, da Faculdade de Direito da Universidade de Nancy, referindo-se à criação desta categoria jurídica nova, tendencia manifiesta a vilargar a liberdade das disposiçães gratúitas e a renovar o seu direito, conclue:

"Il faut toujours reconnaître au juge le droit et même l'obligation de rechercher les intentions du législateur. Mais d'ailleurs il ne s'agit bien entendu que de ses intentions certains et non de celles qu'on pourrait, plus ou moins arbitrairement, lui prêter. Ici plus qu'ailleurs puisqu'il s'agit de prohibitions, il faut s'en tenir à la volonté legislative, dans la mesure où elle peut être nettement degagée".

Dentro deste conceito moderno, a pretensão dos impugnadores do fideicomisso por doação inter-vivos parecenos insustentavel.

Acresce que o legislador, no art. 1.174 do Código Civil, só se referiu e só tratou da reversão dos bens ao doador, por uma necessidade decorrente dos efeitos jurídicos da doação, transmitindo os bens do doador ao donatário. Ora, se o legislador não permitisse a estipulação da reversão, os bens doados passariam ao patrimônio do donatário e por sua morte aos seus herdeiros. Consequentemente, o que se teve em vista foi regular apenas esta situação juridica do 
doador, que desejando beneficiar tão somente o donatário, ficaria privado de seus bens, indo beneficiar terceiros estranhos ao seu desejo, se não lhe fosse conferido o direito de reversão. A disposição foi conferida, portanto, para beneficiar o doador, no caso da morte do donatário ainda em vida do doador, não cogitando o legislador da estipulação a favor de terceiro, nem siquer implicitamente, para proíbi-la.

d) Na doação, ato bilateral, não cabe a estipulação a favor do fideicomissário, estranho wo ato jurídico.

A objeção não nos parece digna de nota, visto como na substituição fideicomissária, pela doação inter-vivos, o fideicomisso não passa de uma estipulação a favor de terceiro, como cláusula perfeitamente ajustavel na doação (vide $\mathrm{C}$. Gonçalves, "Tr. de Dir. civ.", vol. IV, pag. 211).

Isto aliás estaria em perfeita harmonia com os dispositivos do art. 1.098 e $\S$ único do Código Civil, enumerando Clovis, entre os contratos, onde é permitida a estipulação a favor de terceiros, as doações modais (obr. cit., vol. IV, 266).

$O$ direito do terceiro não decorre da sua anuência, mas nasce do próprio contrato (vide Carvalho Santos, obr. cit., vol., XV, pag. 305). Uma vez aceita a doação, com a condição decorrente do fideicomisso, o contrato está perfeito e acabado, nascendo a favor do terceiro o seu direito eventual, ou, como pensam outros, o domínio sob condição suspensiva (vide Josserand, "Cours de dr. positif. fr.", vol. III, n. 1294 e segs).

Tratando das substituições fideicomissárias nas doações, diz Alex WeIl (obr. cit., n. 479):

"Le donateur ne fait pas en notre matière une doation pure et simple; il assortit d'une condition au profit d'un tiers, l'appelé. Les appelés profitent donc en tant que bénéficiaires $d$ 'une stipulation par autrui, d'une convention à laquelle ils nont pas participé". 
Tambem no mesmo sentir se pronuncia Simone CalasTRENG:..

"Desormais toute personne peut s'engager visà-vis d'une outre à accomplir une prestation désignée au bénéfice d'un tiers. C'est une exception à l'indépendance: un droit nait au profit de quelqu'un, en dehors de toute intervention de sa part" ("La relativité des conventions", pag. 212) (Vide Demogue, obr. cit., vol. 7, n. 764).

e) Finalmente, lalega-se que ás doações não se podem aplicar, por analogia, os principios referentes ao fideicomisso, por senem os mesmos de lei especial.

A objeção não procede, pois, como vimos pelas refutações anteriores, as doações inter-vivos comportam a cláusula fideicomissária em virtude dos princípios gerais que regem os atos jurídicos.

Não é necessário recorrer aos preceitos que regem as substituições fideicomissárias do direito sucessório, para aplicá-los às doações.

Mas, atacando a objeção na sua essência, e admitindo-se que os dispositivos referentes às substituições fideicomissárias no testamento sejam preceitos de exceção, ainda assim não procede o argumento, visto como seria procedente o recurso à analogia.

As leis especiais podem constituir preceitos gerais relativos à matéria por elas regulada, de maneira tal, que ha relações jurídicas, de natureza perfeitamente identicas à regulada pela lei especial, que poderão socorrer-se, por analogia, dos preceitos excecionais.

Eis o que nos ensina o notável jurista Giulio Venzi:

"Puó darsi il caso de norme che siano sólo relativamente eccezionali, cioé, pur constituendo una deroga a norme generali di ordine superiore, siano anch'esse alla loro volta generali rispetto alla materia per cui vennero introdotte" ("Nuovo di- 
gesto italiano", vol. I, pag. 436, n. 9 - Conf. Coviello, "Man. de dir. civ. it." - Parte Geral, pag. 85).

Ora, as doações e os testamentos são atos jurídicos que se referem às liberalidades, às disposições a título gratúito, sendo as 'substituições modalidades daqueles institutos, com carater de proteção familiar (vide AlEx WeILl, obr. cit., pag. 817, n. 478; Emile Billette, art. cit. pag. 191; ZaCharieCrome-Barassi, "Man. de dir. civ. fr.", vol. IV, § 654).

Vemos no Código Civil francês, arts. 1.048 a 1.074, a regulamentação das substituições fideicomissárias permitidas quer por atos inter-vivos, quer por testamento (vide Colin et Capitant, "Derecho civ." tr. de D. DE Buen, vol. 8, pag. 169 e segs.).

Ora, se as doações e os testamentos são atos de liberalidade, participando, portanto, da natureza jurídica das disposições a título gratúito em geral, os princípios reguladores das substituições fideicomissárias, como modalidades quer da doação, quer do testamento, devem ser aplicados a ambas as formas de liberalidades.

Se o legislador pátrio regulou as substituições quando tratou da matéria relativa ao testamento, uma das modalidades das disposições a título gratúito, tais dispositivos, quando de carater especial, devem ser aplicados, por analogia, às doações, que tambem são modalidades dos atos jurídicos a título gratúito. 